\title{
Laffer Strikes Again: Dynamic Scoring of Capital Taxes
}

\author{
Holger Strulik* \\ Timo Trimborn**
}

Leibniz Universitat Hannover, Discussion Paper No. 454

ISSN 0949-9962

First Version: July 2010. This Version: October 2010

\begin{abstract}
We set up a neoclassical growth model extended by a corporate sector, an investment and finance decision of firms, and a set of taxes on capital income. We provide analytical dynamic scoring of taxes on corporate income, dividends, capital gains, other private capital income, and depreciation allowances and identify the intricate ways through which capital taxation affects tax revenue in general equilibrium. We then calibrate the model for the US and explore quantitatively the revenue effects from capital taxation. We take adjustment dynamics after a tax change explicitly into account and compare with steady-state effects. We find, among other results, a self-financing degree of corporate tax cuts of about 70-90 percent and a very flat Laffer curve for all capital taxes as well as for tax depreciation allowances. Results are strongest for the tax on capital gains. The model predicts for the US that total tax revenue increases by about 0.3 to 1.2 percent after abolishment of the tax.
\end{abstract}

Keywords: corporate taxation, capital gains, tax allowances, revenue estimation, Laffer curve, dynamic scoring.

JEL: E60, H20, O40.

\footnotetext{
University of Hannover, Wirtschaftswissenschaftliche Fakultaet, 30167 Hannover, Germany; email: strulik@vwl.uni-hannover.de.

** University of Hannover, Wirtschaftswissenschaftliche Fakultät, Königsworther Platz 1, 30167 Hannover, Germany; email: trimborn@vwl.uni-hannover.de
} 


\section{INTRODUCTION}

It is well known that static scoring, the conventional estimation method of tax revenue, ignores important general equilibrium effects. Dynamic scoring of, for example, a corporate tax cut would take into account that firms adjust to the lower tax by paying more dividends and by financing investment to a smaller degree with retained earnings. It would thus take into account that firms will be more leveraged and that households hold smaller parts of their wealth in form of equity and larger parts in form of bonds. This in turn means that households pay less taxes on capital gains and more taxes on dividends and other capital income, a consequence that would also be taken into account by the general equilibrium approach. Moreover, it would take into account that increasing costs from higher leverage may cause firms to grow slower such that, ceteris paribus, firm size is smaller at any given time. This effect taken in isolation leads probably to smaller tax revenue from corporate taxation and capital gains taxation, a fact that would also be taken into account by dynamic scoring.

Considering all the interaction and feedback effects, it is thus not at all obvious how the corporate tax cut affects total tax revenue in general equilibrium. This problem is addressed by the present paper. We provide a dynamic scoring analysis for the corporate tax rate and for other important taxes on capital: taxes on dividends, on capital gains, and on general interest income. We also investigate tax depreciation allowances. ${ }^{1}$

Our analysis is firmly built upon the existing literature on dynamic scoring using the neoclassical growth model, most notably Mankiw and Weinzierl (2006) and Trabandt and Uhlig (2010). We deviate from the existing literature, which usually subsumes all taxes on capital in a single tax rate, by explicitly modeling a corporate sector, the firms' investment and finance problem, and a detailed set of capital taxes. As a result we provide a refined and differentiated assessment of how capital tax changes affect tax revenue. ${ }^{2}$

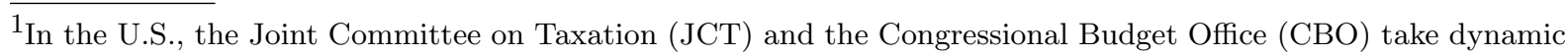
effects on the micro-level into account in their revenue estimations. Both agencies would, naturally, deny to classify their method as being purely static. Here, we define in the spirit of Mankiw and Weinzierl (2006) as dynamic scoring a revenue estimation method that takes general equilibrium effects through, for example, GDP and employment, into account.

${ }^{2}$ Another literature, including Ireland (1994), Bruce and Turnovsky (1999), Agell and Persson (2001), and Novales and Ruiz (2002), investigates the problem in an endogenous growth setup. Whether taxes affect long-run growth is still debated. That taxes affect the level of income per capita, however, as suggested by the neoclassical growth model, is theoretically undisputed and empirically well supported (for recent studies see Romer and Romer (2010) and Mountford and Uhlig (2008)). Our study is also related to the more general analysis of taxes in the neoclassical growth model, which includes, among others, Greenwood and Huffman (1991), Cooley and Hansen (1992), Baxter and King (1993), McGratten (1994), Mendoza and Tesar (1998), and McGratten and Prescott (2005).
} 
A differentiated dynamic scoring of capital taxation is needed to clarify the claim, frequently made by economic scholars and the popular press, that some capital taxes are more distortionary than others. In particular, it has long been argued that corporate and capital gains taxes are so inefficient that tax cuts would largely finance themselves. This argument, however, has never been scrutinized in a dynamic, state-of-the-art general equilibrium setup. The present paper proposes a first step in this direction.

Dynamic scoring is strongly related to but not identical to the dynamic Laffer curve. The dynamic Laffer curve shows for the current tax legislation (a set of given taxes) how the level of a particular tax rate, say $\tau_{i}$ affects total tax revenue $R$, taking behavioral changes (of, for example, labor supply and investment) and the implied revenue changes from other tax rates into account. Formally, dynamic scoring of a tax rate $\tau_{i}$ computes the derivative of the dynamic Laffer curve taken at the point defined by the current tax legislation, i.e. it computes $\mathrm{d} R / \mathrm{d} \tau_{i}$. Since the Laffer curve is typically non-linear and in many cases hump-shaped, taking the derivative provides "only" local information (how much a marginal tax cut reduces revenue) whereas the Laffer curve provides global information (which tax rate yields maximum revenue, how much total revenue is reduced if a tax is cut to zero etc.) Both the curve as such and its derivative are thus providing complementing information.

Dynamic scoring is related to static scoring by the degree of self-financing of a (marginal) tax cut. To see this, let $T_{i}$ denote the tax base of a particular tax $\tau_{i}$ such that total revenue $R=\sum_{j=1}^{n} \tau_{j} T_{j}$. Static scoring for a tax $\tau_{i}$ obtains $\partial R / \partial \tau_{i}=T_{i}$ and predicts that a marginal change of the tax rate increases tax revenue by the size of the tax base. Dynamic scoring takes behavioral changes and general equilibrium effects into account and predicts that an increase of $\tau_{i}$ leads at most to the same and probably to a smaller increase of tax revenue than suggested by static scoring. Suppose dynamic scoring predicts that $\mathrm{d} R / \mathrm{d} \tau_{i}=(1-x)\left(\partial R / \partial \tau_{i}\right), x \leq 1$, i.e. it predicts that a marginal tax increase causes taxes revenue to rise only by $1-x$ percent of the tax base. With respect to a tax cut it thus predicts that tax revenue decreases only by $(1-x)$ percent, where $x=1-\left(\mathrm{d} R / \mathrm{d} \tau_{i}\right) /\left(\partial R / \partial \tau_{i}\right)=1-\left(\mathrm{d} R / \mathrm{d} \tau_{i}\right) / T_{i}$ denotes the degree of self-financing of the tax cut.

The expressions "dynamic Laffer curve" and "dynamic scoring", which we adopt from the literature, are, in fact, a bit misleading. Actually both curve and scoring are in most cases obtained from comparative static analysis of steady-states assumed by an economy before and 
after a tax change, i.e. after all adjustment dynamics have taken place. Comparative static analysis thus underestimates the budgetary effect of capital tax cuts (given that a cut of capital taxes increases the incentive to invest). It fails to take into account that the tax rate decreases immediately whereas the tax base, the capital stock, increases slowly over time. Diagrammatically, comparative steady-state analysis biases the maximum of the Laffer curve to the left. Our study takes this shortcoming into account by computing also, aside from steady-state "dynamic" Laffer curves, "double-dynamic" Laffer curves displaying the net present value of tax revenue collected including transitional dynamics towards the new steady-state.

In order to be comparable with earlier results we relate our study to Trabandt and Uhlig (2010) by using as much as possible their model and their calibration for the US. We show that our model supports a similar Laffer curve for labor taxation and similar results for dynamic scoring of a hypothetical "aggregate capital tax". To be specific, Trabandt and Uhlig study a setup without a corporate sector and thus with just one tax on capital income of households and obtain (by comparing steady-states of the benchmark economy) a degree of self-financing of 51 percent for a cut of the capital tax. Our model with a disaggregated set of capital taxes predicts in the benchmark case a self-financing degree of 67 percent if all taxes on capital are cut simultaneously.

Our novel results are obtained at the disaggregated level. It turns out that different capital tax cuts have indeed very different implications for tax revenue. For example, comparing steadystates we obtain a degree of self-financing of 1 percent for the dividend tax, 47 percent for the tax on private interest income, and 89 percent for the corporate income tax. For the capital gains tax the predicted degree of self-financing is 445 percent, indicating that the US is on the wrong side of the Laffer curve.

These results are modified when adjustment dynamics after a tax cut are taken into account. The influence of adjustment dynamics on the assessment of tax changes varies, again, quite drastically across the different capital taxes. For example, net present value calculations reduce the predicted degree of self-financing for the tax on interest income to 16 percent but leaves it at a relatively high level of 71 percent for the corporate tax and at 219 percent for the capital gains tax.

Overall our analysis confirms that some capital taxes are more distortionary than others. In particular, we predict that corporate taxes and capital gains taxes could be abolished with little 
or no negative impact on tax revenue. Our analysis also shows that the Laffer curve for the investment tax credit is basically horizontal and thus recommends this instrument as particularly suitable for fiscal policy interventions.

The remainder is organized as follows. The next section sets up the model. Section 3 present results from analytical dynamic scoring (in the spirit of Mankiw and Weinzierl, 2006) and reveals the intricate ways through which capital taxation affects tax revenue. An understanding of these channels helps to interpret and explain the numerical results. The stage for this is set in Section 4 which calibrates the model for the US economy. Section 5 obtains self-financing effects and Section 6 dynamic Laffer curves.

\section{THE MODEL}

2.1. Firms. The economy is populated by a continuum $(0,1)$ of corporations, which maximize in favor of their shareholders present value of the firm (as in Sinn, 1987, Auerbach, 2001) and which finance their input bill by retained earnings or costly debt (as in Strulik, 2003, Strulik and Trimborn, 2010). Let $V$ denote the value of a firm and $D$ dividends paid. On the tax side let $\tau_{d}$ denote the tax rate on dividends, $\tau_{p}$ the tax rate on interest income, and $\tau_{c}$ the tax rate on capital gains. No-arbitrage at capital market equilibrium requires that the after-tax return of bonds equals the return obtained from investment in shares consisting of after tax earnings from capital gains and dividends:

$$
\left(1-\tau_{p}\right) r V=\left(1-\tau_{c}\right) \dot{V}+\left(1-\tau_{d}\right) D
$$

Integrating equation (1) and applying the terminal condition that discounted firm value converges to zero for $t \rightarrow \infty$ provides present value of the firm.

$$
V(t)=\int_{t}^{\infty} \frac{\left(1-\tau_{d}\right) D}{1-\tau_{c}} e^{-\int_{t}^{v} \frac{1-\tau_{p}}{1-\tau_{c}} r(s) d s} d v .
$$

In order to model tax depreciation allowances we assume, inspired by Sinn (1987), that a proportion $z$ of a unit of investment can be deducted immediately and that the remainder is tax-deductible over time with the rate of economic depreciation $(\delta)$. We refer to $z$ alternatively as investment tax credit and tax depreciation allowance. Let $R_{r}$ denote the tax revenue from retained profits taxed at rate $\tau_{r}, \Pi$ accounting profits, $I$ net investment and $\dot{B}$ new debt. Gross 
dividends are then defined by (3).

$$
D=\Pi+\dot{B}-I\left(1-z \tau_{r}\right)-R_{r} .
$$

Firms face an exogenously growing level of technology $A$ and produce with constant returns to scale with respect to capital $K$ and labor in efficiency units $A L$. The production function $F$ has positive and decreasing marginal returns. Each unit of labor receives a wage $w$. External finance entails a unit costs of debt which consist of the market interest rate and a further cost depending on the firm's debt ratio $(B / K)$. This cost can be imagined as agency cost of debt, i.e. a deadweight cost that does not show up as factor income elsewhere in the economy (see e.g. Bernanke and Gertler, 1989, Carlstrom and Fuerst, 1997). The explicit shape of the cost function $a(B / K)$ is calibrated such that the steady-state solution for $B / K$ approximates leverage of the average US corporation and the average responsiveness of financial structure to corporate tax changes. ${ }^{3}$

Accounting profits are given by $\Pi=F(K, A L)-w L-\delta K-r B-a(B / K) B-\tau_{r} z I$ and the associated corporate tax revenue is given by $R_{r}=\tau_{r} \Pi$. Inserting these expressions into (3) we get gross dividends (4).

$$
D=\left(1-\tau_{r}\right)\left[F(K, A L)-w L-\delta K-r B-a(B / K) B-\tau_{r} z I+\frac{\dot{B}-\left(1-\tau_{r} z\right) I}{1-\tau_{r}}\right] .
$$

The corporations part of the model is completed by the law of motion for capital

$$
I=\dot{K}
$$

In the Appendix we show that maximization of (2) subject to (4) and (5) leads to the following conditions for employment and capital structure.

$$
\begin{aligned}
w & =A\left[f(k, \ell)-f_{k}(k, \ell) k\right] \\
r+a(b)+a^{\prime}(b) b & =\frac{1-\tau_{p}}{\left(1-\tau_{c}\right)\left(1-\tau_{r}\right)} \cdot r \\
f_{k}(k, \ell)-\delta+a^{\prime}(b) b^{2} & =\frac{\left(1-\tau_{r} z\right)^{2}\left(1-\tau_{p}\right)}{\left(1-\tau_{r}\right)\left(1-\tau_{c}\right)} \cdot r
\end{aligned}
$$

\footnotetext{
${ }^{3} \mathrm{~A}$ micro-foundation of agency costs could be integrated into the model at the expense of further formal complication and notational clutter, see Strulik (2008). Turnovsky (1982, 1990) and Sinn (1987) investigate a similar model without endogenous costs of debt.
} 
where $k$ is capital in efficiency units, $k:=K / A, b$ is the debt ratio, $b:=B / K$, and production per efficiency units is denoted by $f(k, \ell):=F(k, \ell), f_{i}(k, \ell)>0, f_{i i}(k, \ell)<0, i=k, \ell$. Equation (6a) is the standard condition requiring that labor is paid according to its marginal product. Equations (6b) and (6c) implicitly determine optimal firm size $(k)$ and financial structure $(b)$.

Of course, the interior solution holds only when the tax law privileges debt finance, i.e. specifically as long as $\tau_{p}<\tilde{\tau_{p}} \equiv 1-\left(1-\tau_{c}\right)\left(1-\tau_{r}\right)$. Otherwise taxes on private capital income are too high compared to corporate taxes and capital gains taxes such that firms prefer to be completely equity financed. A tax advantage of debt finance is empirically supported for the US and many other OECD countries (OECD, 1991, Graham, 2000, 2006).

2.2. Households. The economy is populated by a continuum $(0,1)$ of households who take all prices and taxes as given, supply $\ell$ units of labor, and maximize their life-time utility from consumption of private goods $C$, leisure $(1-\ell)$, and consumption of goods provided by the government $G$. The utility function displays a constant intertemporal elasticity of substitution and - as proposed in the RBC literature - a constant Frisch elasticity of labor supply such that employment does not change along a balanced growth path. Trabandt and Uhlig (2010), i.e. the study to which our work is perhaps most closely related, took great pain in order to motivate an empirically plausible form of the utility function and we basically adopt their suggested parameterization, but we transform it to fit into our setup in continuous time. This means that households maximize

$$
\max _{C, \ell} \int_{0}^{\infty}\left[\frac{1}{1-\sigma}\left(C^{1-\sigma}\left(1-\kappa(1-\sigma) \ell^{1+\frac{1}{\phi}}\right)^{\sigma}-1\right)+\xi \frac{G^{1-\eta}}{1-\eta}\right] e^{-\rho t} d t
$$

where $\rho$ is the time preference rate, $\phi$ the Frisch elasticity of labor supply, $1 / \sigma$ the elasticity of intertemporal substitution for private consumption, and $1 / \eta$ the elasticity of intertemporal substitution for government consumption. Parameters $\kappa$ and $\xi$ denote weights for disutility of labor and government consumption. For $\sigma=1$ the utility function simplifies to $\max _{C, \ell} \int_{0}^{\infty}\left[\log (C)-\kappa \ell^{1+\frac{1}{\phi}}+\xi \frac{G^{1-\eta}}{1-\eta}\right] e^{-\rho t} d t$.

Households receive a wage $w$ for each unit of supplied labor $\ell$, a rate of return $r$ on bond holdings and transfers $T$ from the government. Financial wealth, $a$, consists of equity holdings, $V$, and bond holdings, $B, a \equiv V+B$. At any time (period) the household receives dividends $D$ and experiences capital gains $\dot{V}$. All sources of income are taxed, possibly at different rates. 
Household pay taxes on labor income at rate $\tau_{w}$, on dividends at rate $\tau_{d}$, on capital gains at rate $\tau_{c}$, on other capital income at rate $\tau_{p}$, and on consumption at rate $\tau_{s}$. Summing up the budget constraint is given by $(8)$.

$$
\dot{B}=\left(1-\tau_{w}\right) w \ell+\left(1-\tau_{p}\right) r B+\left(1-\tau_{d}\right) D+T+\left(1-\tau_{c}\right) \dot{V}-\left(1+\tau_{s}\right) C
$$

After inserting $\dot{B}$ and $\dot{V}$ from (2) into $\dot{a}=\dot{V}+\dot{B}$ the budget constraint simplifies to (9).

$$
\dot{a}=\left(1-\tau_{w}\right) w \ell+\left(1-\tau_{p}\right) r a+T-\left(1+\tau_{s}\right) C .
$$

From the first order conditions we obtain consumption growth according to the Ramsey rule and a condition for the optimal supply of labor. In case of log-utility of consumption these choices are reflected by (10) and (11).

$$
\begin{aligned}
\dot{C} / C & =\left(1-\tau_{p}\right) r-\rho \\
\ell^{\frac{1}{\phi}} & =\frac{\left(1-\tau_{w}\right) w}{\left(1+\tau_{s}\right) \kappa\left(1+\frac{1}{\phi}\right) C} .
\end{aligned}
$$

Seemingly, labor supply is affected only by taxes on labor and growth of consumption $\dot{c} / c-$ and thus the savings rate - is only affected by the capital income tax $\tau_{p}$. Focussing just on (10) (11) households choices thus seem to be identical to those obtained from a much simpler setup without a corporate sector.

In fact, however, there are important interactions and feedback effects at work through noarbitrage (1) and firm size and capital structure (6b)-(6c). Take, for example, a cut of the corporate tax rate. It increases net dividends received by households and induces firms to pay more dividends and finance investment less by retained earnings. As a result firms are more leveraged and households hold smaller parts of their wealth in form of equity stocks and larger parts in form of bonds. This means that firms pay less corporate taxes and households pay less taxes on capital gains and more taxes on dividends and other capital income. Moreover, increasing cost from higher leverage induces firms to grow slower such that, ceteris paribus, firm size is smaller at any given time. This effect taken in isolation leads to smaller tax revenue from corporate taxation and capital gains taxation. The changing size of firms will most likely affect wages and consumption disproportionately, which in turn causes an adjustment of labor supply and feeds back on labor taxes collected and on firm size. Summarizing it is a priori not 
at all clear to what extent a corporate tax cut affects total tax revenue collected. A general equilibrium analysis is needed to assess dynamic scoring of the corporate tax cut.

2.3. Government and general equilibrium. Total tax revenue is spent on purchases of goods $G$ and income transfers to households $T$. Summing up tax revenue collected we obtain the budget constraint (12).

$$
T+G=\tau_{w} w \ell+\tau_{c} \dot{V}+\tau_{r} \Pi+\tau_{d} D+\tau_{p} r B+\tau_{s} C
$$

We assume that the government purchases a given share $g$ of output such that $G=g Y$. If there are any tax revenues remaining they are paid out to households; otherwise the government issues bonds. Using Ricardian equivalence, the path of government debt necessary to balance the budget can be represented by a time series of lump sum income transfers. In other words transfers are residual.

In general equilibrium, GDP is used for private consumption, investment, government purchases, and agency costs $Y=C+I+\delta K+G+a(b) B=F(K, A \ell)$. Inserting this into (6), defining consumption in efficiency units $c:=C / A$, and assuming that technology $A$ grows at a constant rate $\gamma$ we obtain growth of aggregate capital as:

$$
\dot{k} / k=[(1-g) f(k, \ell) / k-a(b) b]-c / k-\delta-\gamma .
$$

The main deviation from the standard neoclassical growth model is that the interest rate is not explicitly given by capital productivity but "only" implicitly determined on the financial market. To see this clearly, derive from (6b) and (6c) financial structure $b$ as an implicit function of firm size $k$. Then conclude from (6b) that the interest rate can be expressed as an implicit function of firm leverage. Using the implicit function theorem, it can then be shown that leverage and interest rates are positively correlated $(\mathrm{d} r / \mathrm{d} b>0)$ and that larger firms are relatively less indebted $(\mathrm{d} b / \mathrm{d} k<0)$. This provides, as for the standard neoclassical growth model, a negative correlation between capital stock and returns $\mathrm{d} r / \mathrm{d} k<0$ and ensures a unique and saddlepointstable equilibrium (See Strulik, 2003, for a detailed explanation and a proof of these claims).

The economy is described by equations (10) and (13) together with (6) and (11) as a dynamic system in $k, c, b, \ell, w$ and $r$. This system exhibits a unique, saddle-point stable steady state to which the economy converges in the long-run. 


\section{Dynamic Scoring of Capital Taxes: Theory}

In this section we provide analytical results of dynamic scoring, i.e. we identify the channels through which, in general, a specific tax change affects total revenue. The insights from theory will guide our explanation of the numerical scoring results obtained later on. Let tax revenue collected from tax base $i$ at rate $\tau_{i}$ be denoted by $R_{i}, i=w, r, p, d, c, s$. Total revenue is then given by $R=R_{w}+R_{r}+R_{d}+R_{p}+R_{s}+R_{c}$ and dynamic scoring of a tax $\tau_{i}$ obtains $\mathrm{d} R / \mathrm{d} \tau_{i}$.

Table 1: Effects of Taxation on Structure of Finance and Firm Size

\begin{tabular}{ccc}
\hline \hline Tax Policy & Structure of Finance & Firm Size \\
\hline $\mathrm{d} \tau_{p}>0$ & $\mathrm{~d} b<0$ & $\mathrm{~d} k<0$ \\
$\mathrm{~d} \tau_{c}>0$ & $\mathrm{~d} b>0$ & $\mathrm{~d} k<0$ \\
$\mathrm{~d} \tau_{r}<0$ & $\mathrm{~d} b>0$ & $\mathrm{~d} k<0$ \\
$\mathrm{~d} \tau_{d}>0$ & $\mathrm{~d} b=0$ & $\mathrm{~d} k=0$ \\
$\mathrm{~d} z>0$ & $\mathrm{~d} b=0$ & $\mathrm{~d} k>0$ \\
\hline
\end{tabular}

Source: Strulik (2003).

We begin with recalling the effects of capital taxation on firm size $k$ and financial structure $b$ at the steady-state. For the present model these effects were derived in Strulik (2003). They are summarized in Table 1. These results are mostly immediately obvious and well-known. Higher taxes on capital gains, private capital income, and (normally) corporate income drive down the incentive to invest and entail smaller firm size at the steady-state. Higher taxes on corporate income and capital gains and lower taxes on private capital income increase the incentive of debt finance. Higher depreciation allowances increase the incentive to invest and leave financial structure unaffected.

The two not so obvious results are the lump sum character of the dividend tax and the degenerate case of corporate income taxation. The dividend tax cancels out at the firm side because maximizing net dividends $\int\left(1-\tau_{d}\right) D \mathrm{~d} t$ is the same as maximizing gross dividends $\int D \mathrm{~d} t$. At the household side the dividend tax cancels out by applying no-arbitrage, i.e. in the transition from (8) to (9). With respect to the corporate tax a degenerate effect occurs if the investment tax credit $z$ is extremely generous. If $z>1-b$ (i.e. larger than 80 percent given our benchmark calibration), higher corporate taxes lead to more investment. Since the US economy is far away from such a situation we exclude it in the subsequent discussion for being purely hypothetical. 
3.1. Corporate Tax. It is useful to begin with exploring how the corporate tax affects GDP. Differentiating the production function we obtain (14)

$$
\frac{\mathrm{d} Y}{\mathrm{~d} \tau_{r}}=\frac{\mathrm{d} A k^{\alpha} \ell^{1-\alpha}}{\mathrm{d} \tau_{r}}=A\left[\alpha k^{\alpha-1} \ell^{1-\alpha} \frac{\mathrm{d} k}{\mathrm{~d} \tau_{r}}+(1-\alpha) k^{\alpha} \ell^{-\alpha} \frac{\mathrm{d} \ell}{\mathrm{d} \tau_{r}}\right] .
$$

Since the economy is growing, the size of any tax effect depends on the current level of technology. This is a pure scale effect, which we will observe throughout the scoring exercise. The direction (sign) of effects is, of course, never affected by the scale.

The effect on capital stock in (14), $\mathrm{d} k / \mathrm{d} \tau_{r}$, is negative (see Table 1). On employment the tax has two opposing effects. A substitution effect leads to less labor supply because wages are lower at the decreased capital stock. Lower $k$, however, means also lower wealth (lower value of shares $V$ ), which leads to higher labor supply. While $\mathrm{d} \ell / \mathrm{d} \tau_{r}$ is thus, generally ambiguous our calibration (in line with Mankiw and Weinzierl, 2006) identifies a dominating substitution effect such that $\mathrm{d} \ell / \mathrm{d} \tau_{r}<0$ and consequently $\mathrm{d} y / \mathrm{d} \tau_{r}<0$.

The effect on corporate tax revenue can be decomposed into three different parts. To see this, write revenue as $R_{r}=\tau_{r} \Pi=\tau_{r} A k(\Pi / K)$ and differentiate totally.

$$
\frac{\mathrm{d} R_{r}}{\mathrm{~d} \tau_{r}}=\frac{\mathrm{d} \tau_{r} A k \Pi / K}{\mathrm{~d} \tau_{r}}=\underbrace{\Pi}_{>0}+A[\underbrace{\tau_{r} \Pi / K \frac{\mathrm{d} k}{\mathrm{~d} \tau_{r}}}_{<0}+\underbrace{\tau_{r} k \frac{\mathrm{d} \Pi / K}{\mathrm{~d} \tau_{r}}}_{<0}] .
$$

The first term, $\Pi$ shows the partial effect of a higher tax rate on corporate tax revenues. This effect is the only one obtained by static scoring. If firms would not react on tax incentives, this would be already the solution: tax revenues would change proportionally to the tax base, i.e. profits.

Dynamic scoring reveals two further effects on $R_{r}$. The second term in (15) indicates the effect through decreasing firm size: A higher corporate tax rate diminishes the incentive to invest. As a consequence, firms are smaller, $\mathrm{d} k / \mathrm{d} \tau_{r}<0$, which mitigates (or even dominates) the expansive effect on tax revenues. This effect is, in principle, also captured by the standard neoclassical growth model without corporate sector where firms are completely financed by debt or equity. There, the effect would be ascribed to a change of the "aggregate" tax on capital income (see Mankiw and Weinzierl, 2006).

The third term in (15) captures the effect on revenue through the channel of firm finance. Inserting the definition of accounting profits and the net investment rate at the steady state 
$(I / K=\gamma)$ we can decompose the finance-effect further into the following expression.

$$
\frac{\mathrm{d} \Pi / K}{\mathrm{~d} \tau_{r}}=\alpha \underbrace{\frac{\mathrm{d} y}{\mathrm{~d} \tau_{r}}}_{<0}-r \underbrace{\frac{\mathrm{d} b}{\mathrm{~d} \tau_{r}}}_{>0}-\underbrace{\frac{\mathrm{d} a(b) b}{\mathrm{~d} \tau_{r}}}_{>0}-z \gamma k-\tau_{r} z \gamma \underbrace{\frac{\mathrm{d} k}{\mathrm{~d} \tau_{r}}}_{<0} .
$$

The first term in (16) shows the negative effect of a lower scale of output on accounting profits, the second term shows the negative effect through higher debt. A higher corporate tax rate implies a higher tax advantage of debt, $\mathrm{d} b / \mathrm{d} \tau_{r}>0$ (see Table 1), and - since costs of debt are tax deductable - lower taxable corporate income. The third term shows the effect from higher leverage and the implied higher agency costs of debt.

$$
\frac{\mathrm{d} a(b) b}{\mathrm{~d} \tau_{r}}=a(b) \frac{\mathrm{d} b}{\mathrm{~d} \tau_{r}}+b a^{\prime}(b) \frac{\mathrm{d} b}{\mathrm{~d} \tau_{r}}>0
$$

since $a^{\prime}(b)>0$. The fact that agency costs of debt are tax deductible entails a further negative effect on returns from corporate taxation.

The final two terms in (16) show the effects through tax allowances. The first of these, $-z \gamma k$, is negative. It captures the fact that a higher corporate tax rate increases the tax deductible part of investment $\tau_{r} z I$. The final term shows a positive effect of second order. Because the tax drives down investment there is less (immediate) tax depreciation of investment, which taken for itself, increases corporate tax revenue. While the sign of the finance-effect is therewith, in principle, indeterminate, we can actually expect that it is negative. The only part of revenue increasing in the tax rate is comparatively small, since $\tau_{r} z<1$ and $\gamma \ll 1$.

Overall we have identified, aside from the static-scoring channel, seven further channels through which corporate taxes affect corporate tax revenue. Of these, six are negative and the seventh is likely to be small. We thus expect a lot of dampening of the positive staticscoring effect. But the analysis is not over yet. A corporate tax change affects also revenue from other taxes.

We begin with the effect on revenue from labor income taxation.

$$
\frac{\mathrm{d} R_{w}}{\mathrm{~d} \tau_{r}}=\frac{\mathrm{d} \tau_{w} w \ell}{\mathrm{d} \tau_{r}}=\frac{\mathrm{d} \tau_{w}(1-\alpha) A y}{\mathrm{~d} \tau_{r}}<0
$$

which is negative because a higher corporate tax rate reduces output and employment (for a reasonable parameter specification of the model, see above). 
Next, consider the effect on revenue from dividend taxation.

$$
\frac{\mathrm{d} R_{d}}{\mathrm{~d} \tau_{r}}=\frac{\mathrm{d} \tau_{d} D}{\mathrm{~d} \tau_{r}}=\frac{\mathrm{d} \tau_{d} V D / V}{\mathrm{~d} \tau_{r}}=\tau_{d} D / V \frac{\mathrm{d} V}{\mathrm{~d} \tau_{r}}<0
$$

Firm value $V$ decreases with increasing corporate tax, both because of smaller firm size $k$ and higher leverage $b$. Since the dividend ratio $D / V$ at the steady-state is independent from corporate taxation (see Appendix), this implies that higher corporate taxes lead to lower total dividends and thus to lower revenue from dividend taxation.

At the steady-state the value of firms increases with the rate of technological progress, $\dot{V} / V=$ $\gamma$, implying that tax revenue from capital gains taxation is given by $R_{c}=\tau_{c} \gamma V$. From the negative effect of corporate taxation on firm value $V$ it follows immediately that

$$
\frac{\mathrm{d} R_{c}}{\mathrm{~d} \tau_{r}}=\tau_{c} \frac{\mathrm{d} \gamma V}{\mathrm{~d} \tau_{r}}<0
$$

A higher corporate tax rate entails lower revenue collected from capital gains.

In order to obtain the effect of corporate taxation on revenue collected from interest income, $R_{p} \tau_{p} r B$, it is helpful to write bond holdings as $B=b K=A b k$. Differentiating revenue totally we obtain (21)

$$
\frac{\mathrm{d} R_{p}}{\mathrm{~d} \tau_{r}}=\frac{\mathrm{d} \tau_{p} r A b k}{\mathrm{~d} \tau_{r}}=\tau_{p} r A b \underbrace{\frac{\mathrm{d} k}{\mathrm{~d} \tau_{r}}}_{<0}+\tau_{p} r A k \underbrace{\frac{\mathrm{d} b}{\mathrm{~d} \tau_{r}}}_{>0} \lessgtr 0 .
$$

The fact that a higher corporate tax entails smaller firms and higher firm leverage has an ambiguous effect on bond holdings of households. Bond holdings increase because of the leverage effect but decrease because of the size effect, which in combination makes the overall effect indeterminate.

Finally, higher corporate taxation has through decreasing wages and decreasing firm size (lower wealth) a negative effect on household consumption (as for the standard neoclassical growth model $\mathrm{d} c / \mathrm{d} k<0$ at the steady-state). This implies lower revenue collected from consumption taxes:

$$
\frac{\mathrm{d} R_{s}}{\mathrm{~d} \tau_{r}}=\tau_{s} \frac{\mathrm{d} C}{\mathrm{~d} \tau_{r}}<0
$$


Summarizing dynamic scoring of the corporate tax rate, we have

$$
\frac{\mathrm{d} R}{\mathrm{~d} \tau_{r}}=\underbrace{\frac{\mathrm{d} R_{r}}{\mathrm{~d} \tau_{r}}}_{\lessgtr 0}+\underbrace{\frac{\mathrm{d} R_{w}}{\mathrm{~d} \tau_{r}}}_{<0}+\underbrace{\frac{\mathrm{d} R_{d}}{\mathrm{~d} \tau_{r}}}_{<0}+\underbrace{\frac{\mathrm{d} R_{p}}{\mathrm{~d} \tau_{r}}}_{\lessgtr 0}+\underbrace{\frac{\mathrm{d} R_{s}}{\mathrm{~d} \tau_{r}}}_{<0}+\underbrace{\frac{\mathrm{d} R_{c}}{\mathrm{~d} \tau_{r}}}_{<0} .
$$

The overall scoring of the corporate tax is indeterminate. If the static-scoring effect dominates, the effect on revenue is positive. But the presence of a multitude of dampening effects on corporate tax revenue itself and through the revenue collected from the other taxes lets us expect that the size of the overall effect will be small. Consequently, we expect a high degree of self-financing for corporate tax cuts.

3.2. Interest Income Tax. The interest income tax is collected from households on private capital income aside from capital gains and dividends, i.e. it is collected from interest on credit supplied from households to firms (on private bonds). From Table 1 we obtain a negative effect on firm size and on leverage $\mathrm{d} k / \mathrm{d} \tau_{p}<0$ and $\mathrm{d} b / \mathrm{d} \tau_{p}<0$. At the steady state, $r^{*}\left(1-\tau_{p}\right)=\gamma \sigma+\rho$, implying a positive effect of the interest income tax on the gross return to capital $\mathrm{d} r^{*} / \mathrm{d} \tau_{p}>0$. Repeating the analysis for the income effect as above verifies that $\mathrm{d} y / \mathrm{d} \tau_{p}<0$.

Applying again the decomposition of debt, $B=A b k$, and totally differentiating revenue from taxing interest income, $R_{p}=\tau_{p} r B$, we obtain (24).

$$
\frac{\mathrm{d} R_{p}}{\mathrm{~d} \tau_{p}}=\frac{\mathrm{d} \tau_{p} r A b k}{\mathrm{~d} \tau_{p}}=r B+A[\tau_{p} r b \underbrace{\frac{\mathrm{d} k}{\mathrm{~d} \tau_{p}}}_{<0}+\tau_{p} b k \underbrace{\frac{\mathrm{d} r}{\mathrm{~d} \tau_{p}}}_{>0}+\tau_{p} r k \underbrace{\frac{\mathrm{d} b}{\mathrm{~d} \tau_{p}}}_{<0}] \lessgtr 0 .
$$

The overall effect can be decomposed into four parts. The first term, $r B$ is the static-scoring effect, suggesting that tax revenue changes with higher taxes proportionally to the tax base. This would be the only effect if firms and households were not reacting on tax incentives and not adjusting their behavior.

The second and third term in (24) reflect adjustment through capital stock and interest rates. These effects would be also observable in a standard neoclassical growth model without corporate sector and firms completely financed by debt. Although the effect from decreasing firm size (through lower investment incentive) and higher returns (through higher gross interest rate) are working in opposite directions it is well-known from calibration exercises of the neoclassical growth model that the compound effect is negative. 
The last term in (24) is the firm-finance effect. A higher tax on interest income of households reduces the tax advantage of debt for firms (which maximize shareholder value in favor of households, see (1) and (2)). Consequently, firms prefer financing through retained earnings and are less leveraged, implying that households hold less bonds. This effect is not captured by the standard neoclassical model and further mitigates tax revenues.

Again, a change of $\tau_{p}$ affects also revenue collected from other taxes. We get a negative effect on revenue from labor taxation $\mathrm{d} R_{w} / \mathrm{d} \tau_{p}=\mathrm{d} \tau_{w}(1-\alpha) A y / \mathrm{d} \tau_{p}<0$ and a negative effect on revenue from consumption taxation $\mathrm{d} R_{s} / \mathrm{d} \tau_{p}=\tau_{s} \mathrm{~d} C / \mathrm{d} \tau_{p}<0$, with the mechanism through wealth and substitution effects as explained above.

The effect on revenue collected from dividend taxation is more complex. Differentiating $R_{d}$ we obtain (25).

$$
\begin{aligned}
\frac{\mathrm{d} R_{d}}{\mathrm{~d} \tau_{p}}=\tau_{d} \frac{\mathrm{d} D}{\mathrm{~d} \tau_{p}}=\tau_{d} & \frac{\mathrm{d} V D / V}{\mathrm{~d} \tau_{p}}=\tau_{d} D / V \frac{\mathrm{d}\left(q_{K} k+q_{B} B\right)}{\mathrm{d} \tau_{p}}=\tau_{d} D / V \frac{\mathrm{d}\left(q_{K} k+q_{B} b k\right)}{\mathrm{d} \tau_{p}} \\
& =\tau_{d} D / V q_{K} \underbrace{\frac{\mathrm{d} k}{\mathrm{~d} \tau_{p}}}_{<0}+\tau_{d} D / V \underbrace{q_{B}}_{<0} \underbrace{\frac{\mathrm{d} b}{\mathrm{~d} \tau_{p}}}_{<0} k+\tau_{d} D / V \underbrace{q_{B}}_{<0} \underbrace{\frac{\mathrm{d} k}{\mathrm{~d} \tau_{p}}}_{<0} b .
\end{aligned}
$$

Here, we have used the fact that the dividend ratio is independent of $\tau_{p}$ (see Appendix), the decomposition of firm value into $V=q_{K} K+q_{B} B$, and the fact that the shadow prices of debt and capital, $q_{B}$ and $q_{K}$, are independent of $\tau_{p}$. There are two counteracting effects on firm value. A positive effect through more equity finance $\mathrm{d} b / \mathrm{d} \tau_{p}<0$, and a negative one through decreasing firm size, $\mathrm{d} k / \mathrm{d} \tau_{p}<0$. The overall effect is thus ambiguous but our numerical evaluations show that the equity-finance effect dominates such that $V$ increases as $\tau_{p}$ rises. This implies also that revenue collected from capital gains rises with $\tau_{p}, \mathrm{~d} R_{c} / \mathrm{d} \tau_{p}=\tau_{c} \mathrm{~d} \gamma V / \mathrm{d} \tau_{p}>0$.

Finally, turning to the impact of interest taxation on revenue from corporate taxation we obtain from differentiating $R_{r}$ that

$$
\frac{\mathrm{d} R_{r}}{\mathrm{~d} \tau_{p}}=\frac{\mathrm{d} \tau_{r} A k \Pi / K}{\mathrm{~d} \tau_{p}}=A[\underbrace{\tau_{r} \Pi / k \frac{\mathrm{d} k}{\mathrm{~d} \tau_{p}}}_{<0}+\tau_{r} k \frac{\mathrm{d} \Pi / k}{\mathrm{~d} \tau_{p}}] .
$$

Again the effect can be decomposed into a firm-size effect and a firm-finance effect. The firm-size effect is reflected by the first term in (26). Lower incentive to invest leads to smaller firm size, $\mathrm{d} k / \mathrm{d} \tau_{p}<0$, which reduces the scale of tax revenues. The firm-finance channel reflected by the 
second term in (26) can be decomposed further into (27).

$$
\frac{\mathrm{d} \Pi / K}{\mathrm{~d} \tau_{p}}=\alpha \underbrace{\frac{\mathrm{d} y}{\mathrm{~d} \tau_{p}}}_{<0}-b \underbrace{\frac{\mathrm{d} r}{\mathrm{~d} \tau_{p}}}_{>0}-r \underbrace{\frac{\mathrm{d} b}{\mathrm{~d} \tau_{p}}}_{<0}-\underbrace{\frac{\mathrm{d} a(b) b}{\mathrm{~d} \tau_{p}}}_{<0}-\tau_{r} z \gamma \underbrace{\frac{\mathrm{d} k}{\mathrm{~d} \tau_{p}}}_{<0} .
$$

The mechanics are similar to those explained in detail with the interpretation of (16) and (17). The difference here is that lower firm leverage leads to higher revenue collected from corporate taxation such that the overall effect is indeterminate.

Summarizing we score for the tax on interest income:

$$
\frac{\mathrm{d} R}{\mathrm{~d} \tau_{p}}=\underbrace{\frac{\mathrm{d} R_{w}}{\mathrm{~d} \tau_{p}}}_{<0}+\underbrace{\frac{\mathrm{d} R_{d}}{\mathrm{~d} \tau_{p}}}_{>0}+\underbrace{\frac{\mathrm{d} R_{p}}{\mathrm{~d} \tau_{p}}}_{\lessgtr 0}+\underbrace{\frac{\mathrm{d} R_{s}}{\mathrm{~d} \tau_{p}}}_{<0}+\underbrace{\frac{\mathrm{d} R_{c}}{\mathrm{~d} \tau_{p}}}_{>0}+\underbrace{\frac{\mathrm{d} R_{r}}{\mathrm{~d} \tau_{p}}}_{\lessgtr 0} .
$$

Compared to the corporate tax there are fewer unambiguously revenue-dampening effects at work and two more effects are actually revenue-amplifying. Although the direction of effects says nothing about their size, we may tentatively expect from this a lower degree of self-financing for interest income tax cuts compared to corporate tax cuts.

3.3. Capital Gains Tax. The capital gains tax has a negative impact on firm size and a positive impact on leverage, $\mathrm{d} k / \mathrm{d} \tau_{c}<0$ and $\mathrm{d} b / \mathrm{d} \tau_{c}>0$ (see Table 1). As for $\tau_{r}$ we obtain $\mathrm{d} y / \mathrm{d} \tau_{c}<0$ and conclude $\mathrm{d} R_{w} / \mathrm{d} \tau_{c}=\mathrm{d} \tau_{w}(1-\alpha) A y / \mathrm{d} \tau_{c}>0$ and $\mathrm{d} R_{s} / \mathrm{d} \tau_{c}=\tau_{s} \mathrm{~d} C / \mathrm{d} \tau_{c}>0$.

At the steady state, the dividend ratio is given by $\left(1-\tau_{d}\right) D / V=\gamma\left(r^{*}-\left(1-\tau_{c}\right)\right)+\rho$ implying $\mathrm{d}(D / V) / \mathrm{d} \tau_{c}>0$. Naturally, a higher tax on capital gains causes firms to pay out more dividends (per share value). Higher dividends as such increase firm value $V$ but imply also lower growth of after-tax $V$ and entail a higher discount of future dividends, a feedback effect that - taken for itself - reduces present value of the firm (see (1) and (2)). The overall effect of $\tau_{c}$ on firm value is thus indeterminate. For the score of capital gains taxes we thus obtain (29)

$$
\frac{\mathrm{d} R_{c}}{\mathrm{~d} \tau_{c}}=\frac{\mathrm{d} \tau_{c} \gamma V}{\mathrm{~d} \tau_{c}}=\gamma V+\tau_{c} \gamma \underbrace{\frac{\mathrm{d} V}{\mathrm{~d} \tau_{c}}}_{\lessgtr 0} \lessgtr 0 .
$$

The first term is the tax-base effect resulting from the fact that firm value grows at the steadystate at the rate of technological progress. The second term is the feedback effect through adjustment of dividend policy. It is, as argued above, indeterminate. 
For revenue from other taxes we apply again the revenue decompositions introduced above and obtain the following results.

$$
\begin{aligned}
\frac{\mathrm{d} R_{p}}{\mathrm{~d} \tau_{c}}= & \frac{\mathrm{d} \tau_{p} r A b k}{\mathrm{~d} z}=\tau_{p} r A(b \frac{\mathrm{d} k}{\underbrace{\mathrm{d} \tau_{c}}_{<0}}+k \underbrace{\frac{\mathrm{d} b}{\mathrm{~d} \tau_{c}}}_{>0}) \lessgtr 0 \\
\frac{\mathrm{d} R_{d}}{\mathrm{~d} \tau_{c}}= & \tau_{d} V \underbrace{\frac{\mathrm{d} D / V}{\mathrm{~d} \tau_{c}}}_{>0}+\tau_{d}(D / V) k \underbrace{\frac{\mathrm{d} q_{K}}{\mathrm{~d} \tau_{c}}}_{>0}+\tau_{d}(D / V) q_{K} \underbrace{\frac{\mathrm{d} k}{\mathrm{~d} \tau_{c}}}_{<0}+\tau_{d}(D / V) b k \underbrace{\frac{\mathrm{d} q_{B}}{\mathrm{~d} \tau_{c}}}_{>0} \\
& +\tau_{d}(D / V) \underbrace{q_{B}}_{<0} k \underbrace{\frac{\mathrm{d} b}{\mathrm{~d} \tau_{c}}}_{>0}+\tau_{d}(D / V) \underbrace{q_{B}}_{<0} b \underbrace{\frac{\mathrm{d} k}{\mathrm{~d} \tau_{c}}}_{<0} \lessgtr 0 \\
\frac{\mathrm{d} R_{r}}{\mathrm{~d} \tau_{c}}= & \frac{\mathrm{d} \tau_{r} k \Pi / k}{\mathrm{~d} \tau_{c}}=\underbrace{\tau_{r} \Pi / k \frac{\mathrm{d} k}{\mathrm{~d} z}}_{>0}+\tau_{r} k \underbrace{\frac{\mathrm{d} \Pi / k}{\mathrm{~d} z}}_{\lessgtr 0} \lessgtr 0 .
\end{aligned}
$$

The mechanisms are working through firm size, leverage, and firm value as explained in connection with $\tau_{r}$ and $\tau_{p}$.

Summarizing, dynamic scoring of the capital gains tax provides the following picture:

$$
\frac{\mathrm{d} R}{\mathrm{~d} \tau_{c}}=\underbrace{\frac{\mathrm{d} R_{w}}{\mathrm{~d} \tau_{c}}}_{<0}+\underbrace{\frac{\mathrm{d} R_{d}}{\mathrm{~d} \tau_{c}}}_{\lessgtr 0}+\underbrace{\frac{\mathrm{d} R_{p}}{\mathrm{~d} \tau_{c}}}_{\lessgtr 0}+\underbrace{\frac{\mathrm{d} R_{s}}{\mathrm{~d} \tau_{c}}}_{<0}+\underbrace{\frac{\mathrm{d} R_{c}}{\mathrm{~d} \tau_{c}}}_{\lessgtr 0}+\underbrace{\frac{\mathrm{d} R_{r}}{\mathrm{~d} \tau_{c}}}_{\lessgtr 0} .
$$

It creates an impression of indeterminacy. In particular it is hard to say whether an increasing capital gains tax will at all raise tax revenue. Below we show that our model calibrated for the US will predict that this is indeed not the case.

3.4. Dividend tax. We have already identified taxes on dividend income as quasi lump-sum, without influence on firm size and structure (Table 1). Seemingly this suggests that there are no further effects from dividend taxation aside from the static-scoring effect. This is, however, not quite true. To see this begin with noting that the net dividend ratio at the steady-state is given by $\left(1-\tau_{d}\right) D / V=\tilde{D} / V=\gamma\left(r^{*}-\left(1-\tau_{c}\right)\right)+\rho$ and is thus independent from dividend taxes, $\mathrm{d}(\tilde{D} / V) / \mathrm{d} \tau_{d}=0$.

Next, obtain how the dividend tax affects firm value.

$$
\begin{array}{r}
\frac{\mathrm{d} V}{\mathrm{~d} \tau_{d}}=\frac{\mathrm{d}\left(q_{K} k+q_{B} b k\right)}{\mathrm{d} \tau_{d}}=\frac{\mathrm{d}\left(\left(1-\tau_{d}\right)\left(1-\tau_{r}^{2} z\right) /\left(1-\tau_{c}\right) k-\left(1-\tau_{d}\right) /\left(1-\tau_{c}\right) b k\right)}{\mathrm{d} \tau_{d}} \\
=\frac{\mathrm{d}\left(1-\tau_{d}\right)}{\mathrm{d} \tau_{d}}\left(\left(1-\tau_{r}^{2} z\right) /\left(1-\tau_{c}\right) k-b k /\left(1-\tau_{c}\right)\right)=-\frac{V}{1-\tau_{d}}<0 .
\end{array}
$$


An increase of $\tau_{d}$ implies a lower value of shares. Now differentiate $\tilde{D} / V$ and insert $\mathrm{d} V / \mathrm{d} \tau_{d}$ :

$$
0=\left(\frac{\mathrm{d} \tilde{D}}{\mathrm{~d} \tau_{d}} V-\frac{\mathrm{d} V}{\mathrm{~d} \tau_{d}} \tilde{D}\right)=\left(\frac{\mathrm{d} \tilde{D}}{\mathrm{~d} \tau_{d}} V+D V\right) \Rightarrow \frac{\mathrm{d} \tilde{D}}{\mathrm{~d} \tau_{d}}=-D
$$

which implies, since $\tilde{D} \equiv\left(1-\tau_{d}\right) D$, that dividend taxation leaves gross dividends $D$ unchanged. This result gives further proof of the fact that dividend taxation does not distort economic behavior.

Summarizing we have the following.

$$
\begin{aligned}
& \frac{\mathrm{d} R_{d}}{\mathrm{~d} \tau_{d}}=D \\
& \frac{\mathrm{d} R_{c}}{\mathrm{~d} \tau_{d}}=\tau_{c} \gamma \frac{\mathrm{d} V}{\mathrm{~d} \tau_{d}}=-\tau_{c} \gamma \frac{V}{1-\tau_{d}}<0 .
\end{aligned}
$$

The static-scoring effect is reduced by a scale effect on firm value. However, since both $\tau_{c}$ and $\gamma$ are small, we expect this dampening effect to be small and thus almost no self-financing of dividend tax cuts.

3.5. Depreciation Tax Allowance. We begin with noting from Table 1 that $\mathrm{d} b / \mathrm{d} z=0$ and $\mathrm{d} k / \mathrm{d} z>0$. Again, we obtain analogously to the analysis of $\tau_{r}$ that $\mathrm{d} y / \mathrm{d} z>0$. From this we conclude positive income and wealth effects on taxes collected from labor income and consumption, $\mathrm{d} R_{w} / \mathrm{d} z=\mathrm{d} \tau_{w}(1-\alpha) A y / \mathrm{d} z>0$ and $\mathrm{d} R_{s} / \mathrm{d} z=\tau_{s} \mathrm{~d} C / \mathrm{d} z>0$.

Applying the revenue decomposition introduced above we obtain the following.

$$
\begin{aligned}
\frac{\mathrm{d} R_{d}}{\mathrm{~d} z} & =\tau_{d} D / V k \underbrace{\frac{\mathrm{d} q_{K}}{\mathrm{~d} z}}_{<0}+\tau_{d} D / V q_{K} \underbrace{\frac{\mathrm{d} k}{\mathrm{~d} z}}_{>0}+\tau_{d} D / V \underbrace{q_{B}}_{<0} b \underbrace{\frac{\mathrm{d} k}{\mathrm{~d} z}}_{>0} \lessgtr 0 \\
\frac{\mathrm{d} R_{p}}{\mathrm{~d} z} & =\frac{\mathrm{d} \tau_{p} r A b k}{\mathrm{~d} z}=\tau_{p} r A b \underbrace{\frac{\mathrm{d} k}{\mathrm{~d} z}}_{>0}>0 \\
\frac{\mathrm{d} R_{c}}{\mathrm{~d} z} & =\tau_{c} \frac{\mathrm{d} \gamma V}{\mathrm{~d} z} \lessgtr 0 \\
\frac{\mathrm{d} R_{r}}{\mathrm{~d} z} & =\frac{\mathrm{d} \tau_{r} A k \Pi / K}{\mathrm{~d} z}=A[\underbrace{\tau_{r} \Pi / K \frac{\mathrm{d} k}{\mathrm{~d} z}}_{>0}+\tau_{r} k \frac{\mathrm{d} \Pi / K}{\mathrm{~d} z}] .
\end{aligned}
$$

Again, the effect on corporate tax revenue can be decomposed into two parts. The first term reflects the firm-size effect. A higher investment credit increases the incentive to invest and, hence, capital accumulation. Firms are bigger, $\mathrm{d} k / \mathrm{d} z>0$, implying more tax revenue. The 
second effect captures losses of tax revenues due to higher investment tax credits. We decompose it into:

$$
\frac{\mathrm{d} \Pi / K}{\mathrm{~d} \tau_{p}}=\alpha \underbrace{\frac{\mathrm{d} y}{\mathrm{~d} z}}_{>0}-\tau_{r} \gamma k-\tau_{r} z \gamma \underbrace{\frac{\mathrm{d} k}{\mathrm{~d} z}}_{>0} \lessgtr 0 .
$$

The sign of the overall effect is indeterminate, but numerical simulations confirm a negative sign. Overall the investment tax credit scores as follows.

$$
\frac{\mathrm{d} R}{\mathrm{~d} z}=\underbrace{\frac{\mathrm{d} R_{w}}{\mathrm{~d} z}}_{>0}+\underbrace{\frac{\mathrm{d} R_{d}}{\mathrm{~d} z}}_{\lessgtr 0}+\underbrace{\frac{\mathrm{d} R_{p}}{\mathrm{~d} z}}_{>0}+\underbrace{\frac{\mathrm{d} R_{s}}{\mathrm{~d} z}}_{>0}+\underbrace{\frac{\mathrm{d} R_{c}}{\mathrm{~d} z}}_{\lessgtr 0}+\underbrace{\frac{\mathrm{d} R_{r}}{\mathrm{~d} z}}_{\lessgtr 0} .
$$

Strikingly most of the revenue effects are positive, indicating that higher tax allowances for investment may actually lead to more tax revenue.

\section{Calibration}

We calibrate the model with U.S. data and a strong reference to related calibration studies. We use a Cobb-Douglas production function and set the capital share $\alpha$ to 0.38 (as in Trabandt and Uhlig, 2010). For the costs of debt we impose an isoelastic function $a(b)=a_{0} b^{a_{1}}$ and try to find parameters $a_{0}$ and $a_{1}$ such that the simulated behavior of the representative corporation generates the correlation between taxation and leverage estimated for the average U.S. corporations by Gordon and Lee $(2001,2007)$. We set $\tau_{r}=0.35$ according to the marginal tax rate applying for U.S. corporations at the highest tax bracket. For tax rates on private capital income we calibrate the initial steady-state such that it reflects the U.S. tax law before the (mostly temporary) tax cuts of the Bush administration. Assuming that the representative household earns the average income of a citizen of the U.S., he or she faces an income tax according to the IRS (2009) of 0.25 . We thus set $\tau_{p}=0.25=\tau_{d}=0.25$. We set the corporate tax rate to $\tau_{r}=0.35$ according to the top tax bracket for corporate taxable income and set the statutory capital gains tax to 0.2 . In the model the tax on capital gains is an effective rate and following Poterba (2004) we set $t_{c}=0.2 / 4$. In order to compare with Trabandt and Uhlig (2010) we set $\tau_{w}=0.28, \tau_{s}=0.05$, and a government spending share on output of $G / Y=0.18$. We adopt $\gamma=0.015$ from various other calibration studies.

The remaining parameters are determined in the following way. Eqs. (6b) and (6c) together with (12) evaluated at the steady state are required to support $b^{*}=0.194$ (the average debt 
ratio of US corporations according to Gordon and Lee, 2001, 2007), a long-run capital output ratio of $k^{* 1-\alpha}=2.38$ (Trabandt and Uhlig, 2010), and a long-run gross investment ratio of $(I+\delta K) / K \cdot(K / Y)=(\delta+\gamma) k^{* 1-\alpha}=0.17$ (US Bureau of Economic Analysis, 2009). This implies $\delta=0.064$ and a net investment ratio $I / K$ of 3.24 .

Preference parameters are set as suggested by Trabandt and Uhlig (2010). For the benchmark run we set $\sigma=2$, implying that $\rho=0.039$ and $r^{*}=0.092$. We set the Frisch elasticity of labor supply to $\phi=1$ and adjust $\kappa$ such that at the steady-state households supply a quarter of their time on the labor market $\left(\ell^{*}=0.25\right)$. This implies $\kappa=3.14$. Since our results depend most heavily on the choice of these two elasticities (and the implied responsiveness of labor supply and investment to tax changes) we provide sensitivity analysis for $\sigma$ and $\phi$. To keep the interest rate and labor supply at the initial steady state constant, we vary $\rho$ and $\kappa$ to match $r^{*}$ and $\ell^{*}$ of the benchmark run.

Following Sinn (1987), we use the steady-state interest rate and the estimates of economic and tax depreciation provided by House and Shapiro (2008) and set $z=0.4$. Fixing a unique $z$ is of course a compromise because economic and tax depreciation varies a great deal across capital goods. For example, we estimate from the House and Shapiro data $z=0.2$ for computers and software, $z=0.47$ for general industrial equipment, and $z=0.48$ for vehicles. Finally, we determine the parameters of the debt cost function by requiring $a(b)=0$ for $b=0$ and that our benchmark economy reproduces Gordon and Lee's (2001) estimate that a five percentage point increase in $\tau_{r}$ raises the debt ratio by about 1.8 percentage points. This provides the estimates $a_{0}=7.63$ and $a_{1}=4.69 .^{4}$

Table 2 summarizes the calibration and its implications. The implied values correspond nicely with those obtained by Trabandt and Uhlig (2010, henceforth TU). The implied consumption share of 65 percent coincides well with TU's share of consumption plus exogenous imports (64 percent). The implied tax revenue collected from labor taxes $T_{w}$ is 17.4 percent of GDP (TU obtain 17 percent from their model and 14 percent from their empirical estimate). In order to compare capital tax revenue with TU we sum up revenues in $R_{k}, R_{k} \equiv R_{r}+R_{c}+R_{p}+R_{d}$ and obtain a value of 10.6 percent of GDP. The corresponding value of TU is 7 percent implied by the model and 9 percent implied by their empirical estimate. Finally, our implied revenue from

\footnotetext{
4 An even larger effect of corporate taxes on firm finance than suggested by Gordon and Lee's estimate has recently been found by Djankov et al. (2008) in a cross-country study. They estimate that a 10 percentage point increase of the corporate tax rate raises the debt to equity ratio by 45 percentage points.
} 
Table 2: Model Calibration and Implications

\begin{tabular}{lccc}
\hline \hline description & notation & value & source \\
\hline capital share & $\alpha$ & 0.38 & Trabandt and Uhlig (2010) \\
inverse of IES & $\sigma$ & 2 & Traband and Uhlig (2010) \\
Frisch elasticity & $\phi$ & 1 & Traband and Uhlig (2010) \\
labor income tax & $\tau_{w}$ & 0.28 & Traband and Uhlig (2010) \\
consumption tax & $\tau_{s}$ & 0.05 & Traband and Uhlig (2010) \\
gov. purchases/GDP & $G / Y$ & 0.18 & Traband and Uhlig (2010) \\
capital output ratio & $K / Y$ & 2.38 & Traband and Uhlig (2010) \\
labor supply & $\ell^{*}$ & 0.25 & Traband and Uhlig (2010) \\
investment tax credit & $z$ & 0.4 & House and Shapiro (2008) \\
gross investment rate & $(I+K) / Y$ & 0.17 & BEA(2009) \\
debt ratio & $b^{*}$ & 0.194 & Gordon and Lee $(2001,2007)$ \\
agency costs & $=a_{0} b^{a_{1}}$ & $a(b)=7.6 b^{4.6}$ & Gordon and Lee $(2001,2007)$ \\
capital income tax & $\tau_{p}$ & 0.25 & IRS (2009) \\
corporate tax & $\tau_{r}$ & 0.35 & IRS (2009) \\
dividend tax & $\tau_{d}$ & 0.25 & IRS (2009) \\
capital gains tax & $\tau_{c}$ & $0.2 \times 0.25$ & Poterba (2004) \\
weight of labor & $\kappa$ & 3.14 & implied \\
economic depreciation & $\delta$ & 0.056 & implied \\
time preference & $\rho$ & 0.039 & implied \\
consumption/GDP & $C / Y$ & 0.65 & implied \\
revenue from labor tax/GDP & $R_{w}$ & 0.174 & implied \\
revenue from capital tax/GDP & $R_{k}$ & 0.106 & implied \\
revenue from cons. tax/GDP & $R_{s}$ & 0.032 & implied \\
gov. transfers/GDP & $T$ & 0.083 & implied \\
\hline \hline
\end{tabular}

consumption taxes is 3.2 percent of GDP while TU obtain 3 from data and model. As a residual of revenue and expenditure we obtain government transfers to households of 8.3 percent of GDP (TU 8 percent). In conclusion the model's predictions are, generally, close to the data and close to those of TU with a mild overestimation of revenue collected from labor taxation and a quite precise estimation of revenue collected from capital taxation.

\section{Dynamics Scoring: Quantitative Results}

We begin with results from marginal analysis, the next section turns to a global analysis, i.e. dynamic Laffer curves. Following Trabandt and Uhlig we approximate derivatives with central differences by calculating $\mathrm{d} R / \mathrm{d} \tau_{i} \approx\left[R\left(\tau_{i}+\epsilon\right)-R\left(\tau_{i}-\epsilon\right)\right] / 2 \epsilon$ for any tax $\tau_{i}$ and set $\epsilon=0.01$. Table 3 shows the degree of self-financing for our set of taxes.

We begin with focussing on total steady-state effects, which are shown in the left column of Table 3 and, for comparison, we first look at the self-financing degree of a labor tax cut. The total steady-state effect can be compared directly with Trabandt and Uhlig (2010). Our result 
TABle 3: Self-FinANCING DEGREE OF TAX CUTS

\begin{tabular}{ll|cc|cc}
\hline \hline Tax & & Steady State & & Net Present Value & \\
& & total & primary & total & primary \\
\hline$\tau_{w}$ & (labor) & 41.8 & 23.2 & 35.3 & 19.9 \\
$\tau_{r}$ & (corporate) & 89.4 & 43.6 & 71.3 & 42.3 \\
$\tau_{p}$ & (interest) & 47.6 & 6.6 & 15.7 & 7.3 \\
$\tau_{c}$ & (capital gains) & 445 & 1.3 & 219 & 15.3 \\
$\tau_{d}$ & (dividends) & 1.4 & 0 & 1.4 & 0 \\
$z$ & (depreciation) & 233 & 20.7 & 121 & 12.0 \\
\hline & aggregate capital tax & 67.3 & 28.9 & 50.2 & 28.2 \\
\hline \hline
\end{tabular}

Self-financing degree of marginal tax cuts in percent (marginal increase in case of the investment tax credit $z$ ). The primary effect is the degree of self-financing through revenue of the tax that has been cut, i.e. through $R_{i}$ when $\tau_{i}$ has been changed $i=w, p, r, c, d$. For $z$ the primary effect is the degree of self-financing through $R_{r}$.

predicts for the US a self-financing degree of about 42 percent, which is about ten percentage points higher than predicted by Trabandt and Uhlig. Their lower estimate originates probably from the assumption that there is just a single tax on capital, which fails to capture important feedback effects from double taxation of capital income. This can be seen as follows. Because labor taxes are lower and net wages are higher, households supply more labor, earn more labor income, and consume and invest more. Higher investment leads to more capital and, in our setup, to higher tax revenue from corporate income (because firms are bigger), from interest income (because capital structure does not change, implying that total debt of firms and thus total bonds of households increase), and from dividend income (because firm value increases and the dividend ratio remains constant, implying more dividends paid out).

There exist a second exercise with which we can compare with the already available literature. For that purpose we assume a simultaneous cut of all individual taxes on capital and compute the weighted sum of the individual self-financing degrees where the weights are the contribution of the individual taxes to total revenue. This gives us an "aggregate" capital tax cut, which can be compared with a cut of the single capital tax available in the standard neoclassical model. For that Trabandt and Uhlig predict a self-financing degree of 51 percent whereas our prediction is about 66 percent, i.e. about 15 percentage points larger. Again, the difference results probably from the feedback effects of double taxation of capital income at the side of corporations and households. 
We now come to our novel results on dynamic scoring of the individual taxes on capital. Here we get a very differentiated picture. The analysis confirms what was already predicted in the theory-section: tax cuts on corporate income provide a much a higher degree of self-financing (of 89 percent) compared to private interest income (of 47 percent). The US calibration also confirms the prediction of a very small self-financing degree of a dividend tax cut.

For the capital gains tax our analysis identifies the US as being on the wrong side of the Laffer curve and predicts a self-financing degree of over 400 percent. Similar results are obtained for the investment tax credit, for which the model predicts a self-financing degree of over 200 percent.

For a correct assessment of these magnitude, however, some qualifications are in order. First of all, dynamic scoring investigatess marginal changes, i.e. local effects for small changes of tax rates. Only from global analysis (i.e. dynamics Laffer curves, to which we turn later) we can draw conclusions with respect to drastic cuts of taxes (or drastic hikes of the investment tax credit). Secondly, the first column of Table 3 shows "only" steady-state effects. Revenue effects from tax cuts that are expansive in the long-run are typically dampened by transitional dynamics. Intuitively, any cut of a capital tax that leads to higher investment increases the tax base (firms size and shares and bonds hold by households) only in the medium and long-run through rising accumulation of capital. The negative revenue effect through the lower tax rate, however, is immediately present.

In order to take adjustment dynamics into account, we compute the net present value of revenue and the associated self-financing degree as follows. We simulate transitional dynamics resulting from a marginal tax cut of 0.1 percentage point. For this purpose we employ the relaxation algorithm as proposed by Trimborn et al. (2008). The advantage of this method is that it nowhere requires a linearization or other approximation of the economic model and allows to obtain impulse responses up to an arbitrarily small, user-specified error. We calculate the tax revenues for each point of time and integrate the discounted stream of revenues in order to get the net present value of revenues. As the discount rate we use the time varying net interest rate $\left(1-\tau_{p}\right) r$, i.e. the interest rate that the government has to pay for its debt.

Table 3 shows that the impact of transitional dynamics varies tremendously across taxes. In particular self-financing of a tax cut of interest income is reduced to a mere 15 percent when transitional dynamics are taken into account. In contrast, results for corporate taxation are relatively robust against inclusion of transitional dynamics. For an intuition, note that a cut 
of $\tau_{p}$ affects the savings rate and growth (recall the Ramsey rule to see that) and thus draws its expansive power predominantly from higher growth, i.e. from gains that materialize only in the medium and long-run. In contrast, corporate taxation operates predominantly through the finance decision of individual firms. Firms adjust their debt ratio immediately to exploit lower tax rates on retained earnings. This effect operates in the short-run and in the long-run.

It is also illuminating to distinguish from the total degree of self-financing the self-financing brought in by revenue collected from the tax that has been cut. We call this the primary degree of self-financing. In particular the corporate tax displays quite a high primary degree of self-financing. The US calibration confirms here again our prediction from theory, which has revealed a multitude of effects operating through firm size and financial structure that dampen the effect of $\tau_{r}$ on $R_{r}$.

For the interest income tax we observe the reverse: the degree of primary self-financing of a tax cut is very low, indicating that the tax is actually quite efficient in collecting revenue from its tax base. The tax acquires its inefficiency mainly from its negative repercussions on growth and thus the scale at which taxes are collected from other sources. This conclusion is even more evident for the capital gains tax for which primary self-financing is insignificant and feedback effects on revenue from other taxes through investment and growth are huge.

We can exploit the idea of total and primary self-financing to explain timing of revenue collection and the different steady-state and NPV performance of cuts of taxes on corporate income and on private interest income. Figure 1 shows adjustment dynamics for total and primary self-financing. For $\tau_{p}$ (reflected by dashed lines) the small primary effect is almost constant over time whereas the total effect is initially negative and dominating. This behavior reflects, again, the fact that $\tau_{p}$ works mainly through growth. After the tax cut, households save more and firms investment more, which, in the first place, leads to less revenue from consumption taxation and corporate taxation. The positive, expansive effects through growth and capital accumulation become dominating only in the long-run. Negative transitional dynamics reduce the self-financing power of $\tau_{p}$ considerably.

The corporate tax cut, in contrast, is immediately effective in producing a primary selffinancing effect of 40 percent through restructuring of firm finance and assets hold by households. Instantly, primary and total self-financing almost coincide. Over time, however, the expansive power of induced growth adds further self-financing through taxes collected from other sources 
Table 4: Sensitivity Analysis: Self-Financing of Tax Cuts

\begin{tabular}{l|c|c|c|c}
\hline \hline \multicolumn{5}{c}{ Part I: Steady-State } \\
\hline Tax & $\sigma=1 \phi=1$ & $\sigma=2 \phi=1$ & $\sigma=1 \phi=3$ & $\sigma=2 \phi=3$ \\
\hline$\tau_{w}$ & 34.9 & 41.8 & 52.5 & 69.6 \\
$\tau_{r}$ & 87.9 & 89.4 & 91.6 & 95.1 \\
$\tau_{p}$ & 43.4 & 47.6 & 54.1 & 64.5 \\
$\tau_{c}$ & 426 & 444 & 473 & 519 \\
$\tau_{d}$ & 1.36 & 1.36 & 1.36 & 1.36 \\
$z$ & 222 & 233 & 249 & 274 \\
\hline aggregate capital tax & 65.7 & 67.28 & 69.7 & 73.5 \\
\hline \multicolumn{5}{|c|}{ Part II: Net Present Value } \\
\hline Tax & $\sigma=1 \phi=1$ & $\sigma=2 \phi=1$ & $\sigma=1 \phi=3$ & $\sigma=2 \phi=3$ \\
\hline$\tau_{w}$ & 30.3 & 35.3 & 46.4 & 59.7 \\
$\tau_{r}$ & 72.6 & 71.3 & 78.1 & 78 \\
$\tau_{p}$ & 16.6 & 15.7 & 29.9 & 33.4 \\
$\tau_{c}$ & 235 & 219 & 304 & 306 \\
$\tau_{d}$ & 1.36 & 1.36 & 1.36 & 1.36 \\
$z$ & 128 & 121 & 165 & 168 \\
\hline aggregate capital tax & 51.3 & 50.2 & 56.8 & 57.2 \\
\hline \hline
\end{tabular}

Self-financing degree of marginal tax cuts in percent (marginal increase in case of the investment tax credit $z$ ). The aggregate capital tax considers a simultaneous cut of all taxes on capital and computes the weighted sum of self-financing degrees where the weights are the contribution of the taxes to total revenues.

Figure 1: Self financing: Total effect (left) - Primary effect (Right)
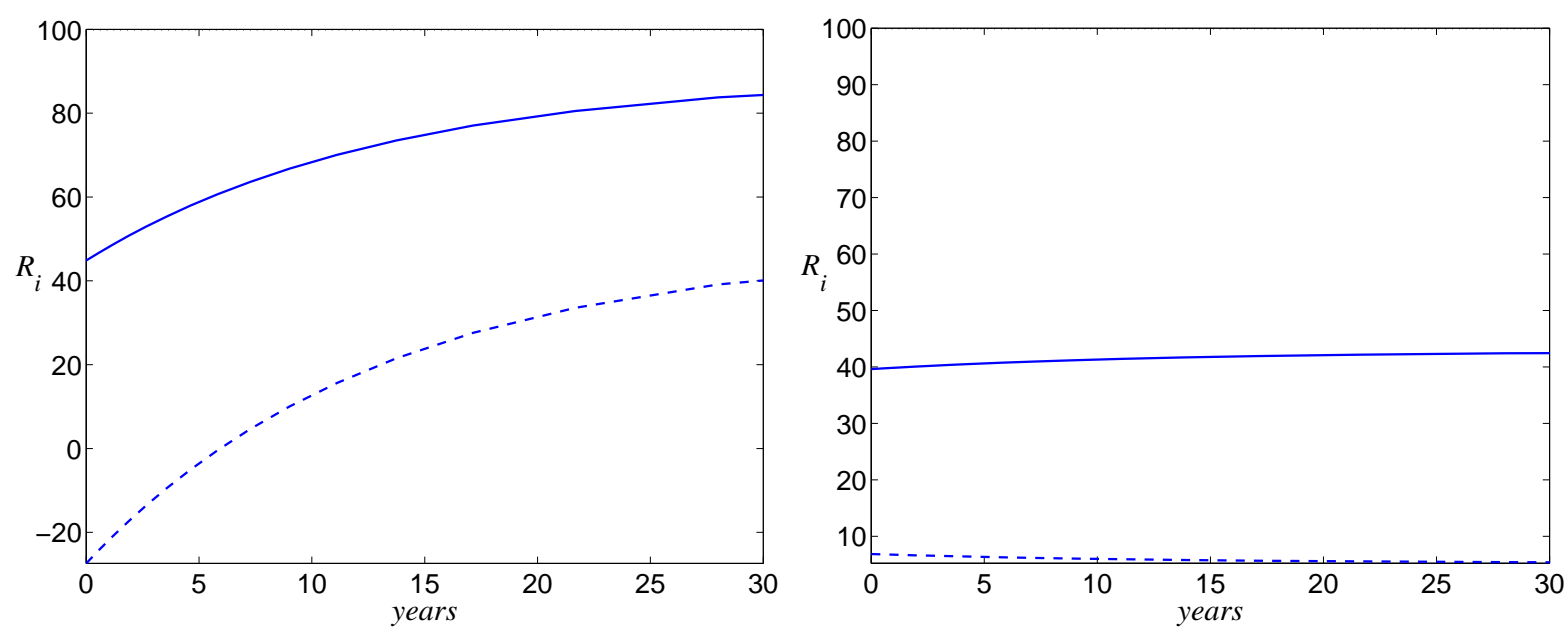

Adjustment dynamics following a 1 percent tax cut. Solid lines: self-financing effect $\tau_{r}$; dashed lines: self-financing effect of $\tau_{p}$.

(through the generally higher scale of the economy). This means that self-financing of tax cuts on corporate income is already positive in the short-run and gets even larger over time. 
As always, results depend on the assumed behavioral responses of savings and labor supply after a tax cut, i.e. on parameters $\sigma$ and $\phi$ of the utility function. As a robustness check we thus provide in Table 4 results for four alternative scenarios. Case 1 considers a popular case of RBC theory, $\log$ utility from consumption $(\sigma=1)$ and a Frisch elasticity of labor supply of unity. Case 2 re-iterates our benchmark case (where $\sigma=2$ ). For both values of $\sigma$ we alternatively consider a much higher Frisch elasticity of labor supply of 3 (see Trabandt and Uhlig (2010) for a detailed discussion of implications of these settings).

As a rule we observe that the self-financing degree is increasing in both elasticities. For $\phi$ this is immediately intuitive. Facing a higher labor supply elasticity, households adjust to higher wages (because of higher capital stock at lower taxes) by supplying more labor, which amplifies any expansive effect of a tax cut and rises the tax base and thus revenue collected.

The most striking result from Table 4 is perhaps the robustness of the self-financing degree for corporate tax cuts. This figure varies between 87 and 95 percent when we compare steady-states and between 71 and 78 percent when we include adjustment dynamics. Self-financing degrees for all other taxes (besides the insignificant dividend tax) react much more sensitively on changing specification of preferences.

In general, our estimates are more robust for capital taxation compared to labor taxation, a result that we share with Trabandt and Uhlig (2010). This can best be seen by inspecting the aggregate tax cut of all capital taxes. The predicted self-financing degree varies "only" between 66 and 73 percent whereas the self-financing degree of labor tax cuts is estimated to vary between 35 and 70 percent.

\section{Dynamic Laffer Curves}

An inspection of dynamic Laffer curves is needed in order to assess to which extent conclusions derived from dynamic scoring, i.e. from marginal analysis, are also global results that hold for drastic changes of taxes. A Laffer curve for a tax on base $i$ shows how tax revenue $R$ is generated relative to the initial steady-state when the tax is raised to $\tau_{i}$ (how much revenue is lost when the tax is cut). This means that Laffer curves are context-specific. Their shape depends on the initial design of the tax system; for any tax they go through the point (initial tax, 100\%).

Again we compute steady-state Laffer curves (which compare revenues at the initial steadystate and at the steady-state assumed after the tax change) and net-present-value Laffer curves 
(which take adjustment dynamics after a tax change into account). Because changes of capital taxes affect the tax base, capital stock, only gradually through investment, we expect that the maximum of the NPV Laffer curve lies, in general, at the right hand side of the maximum of the steady-state Laffer curve. By ignoring adjustment dynamics the steady-state Laffer curve underestimates the power of tax hikes in collecting revenue.

Figure 2: Laffer Curves: Labor Income (left) - Corporate Income (Right)
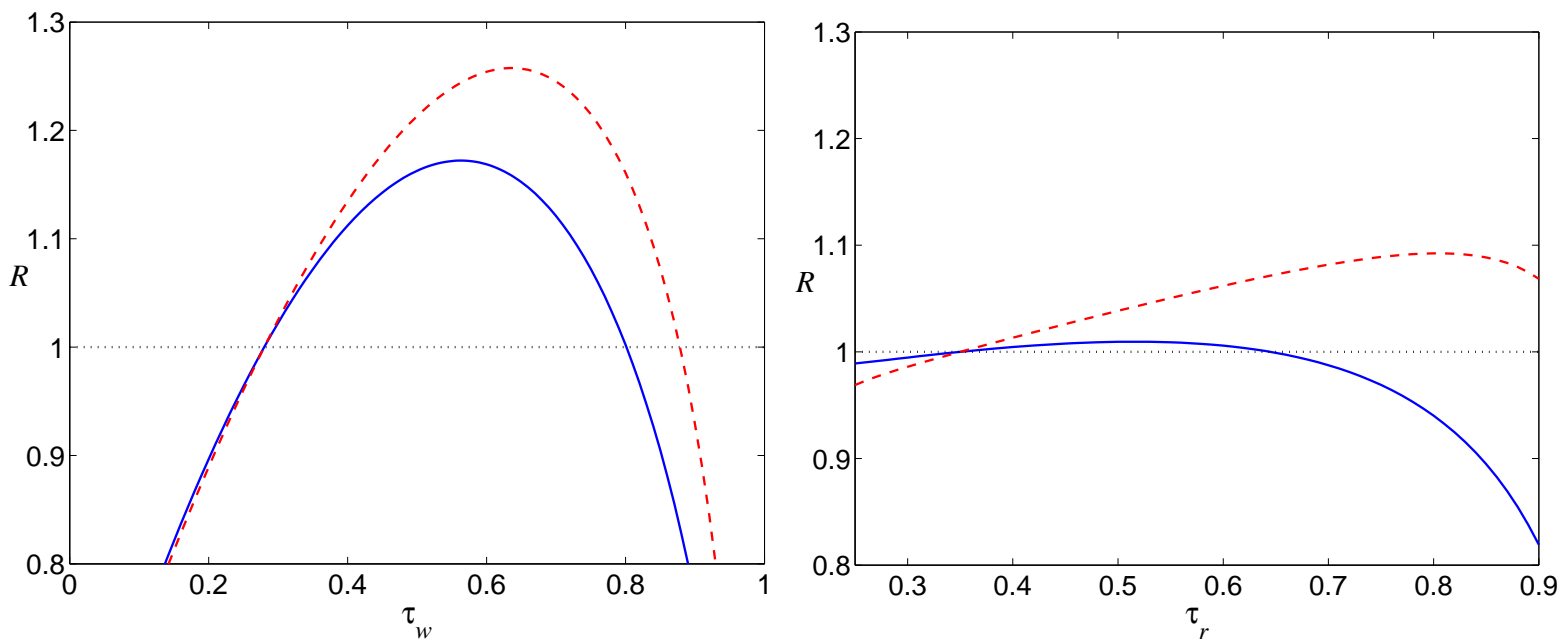

Solid lines: steady-state Laffer curve; dashed lines: NPV Laffer curve.

Figure 2 conveys the main message of our Laffer curve analysis. It shows steady-state and NPV Laffer curves for taxes on labor income and on corporate income. For comparison we have used the same scale on the revenue axes. The main impression is how relatively flat the Laffer curve for corporate taxation is.

The Laffer curve for taxation of labor income broadly confirms Trabandt and Uhlig (2010). Coming from an initial tax rate of 0.28 the curve is relatively steeply increasing and reaches a maximum for $\tau_{w}=0.57$ (Tranbandt and Uhlig: 0.63). At the maximum the government is predicted to collects about 17 percent more revenue than at the status quo. Taking adjustment dynamics into account moves the maximum further to the right to 0.64 and raises the gain of tax revenue (in net present value terms) to 26 percent. $^{5}$

The Laffer curve for taxation of corporate income, in contrast, is relatively flat, in particular the steady-state variant. The maximum is where $\tau=0.52$ but this value is only informative in connection with the figure for maximum revenue, which is just 0.9 percent above status quo

\footnotetext{
${ }^{5}$ The intersection between steady-state- and NPV-Laffer curve identifies the status quo tax rate.
} 
revenue, reflecting the flatness of the curve. These estimates are lower than Trabandt and Uhlig's findings for an aggregate capital tax (they predict a maximum at 63 and revenues of 6 percent above the status quo). The Laffer curve gets somewhat more hilly when adjustment dynamics are taken into account. The maximum is now at 0.8 and maximum revenue raises to 9 percent above the status quo level.

It is more interesting, however, to explore the Laffer curve in the other direction, towards lower taxes. Here our results predict that taxes can be reduced to a large extent with little consequence on revenue. Unfortunately, the Laffer curve ends at $\tau_{r}=0.21$, which is the tax rate below which the tax advantage of debt finance is lost and the model converges to the corner solution of a completely equity financed firm (the standard neoclassical growth model). Without integrating the corner solution explicitly in our analysis we can thus "only" conclude that the corporate tax could be reduced by about 14 percentage points without any significant consequence on tax revenue.

Naturally, the problem of a corner solution occurs again for taxation of interest income. If $\tau_{p}$ rises above 0.38 our model predicts that corporations prefer to be completely equity financed and the model converges toward the corner solution. With respect to tax cuts, however, a corner is no problem and Figure 3 demonstrates the relative flatness of the Laffer curve for interest income taxation by using again the same scale as for labor income taxation. The maximum of the Laffer curve lies in the region where $\tau_{p}$ is so high that firms are completely equity financed and is thus not visible.

Figure 3: Laffer Curves: Interest Income (left) - Capital Gains (Right)
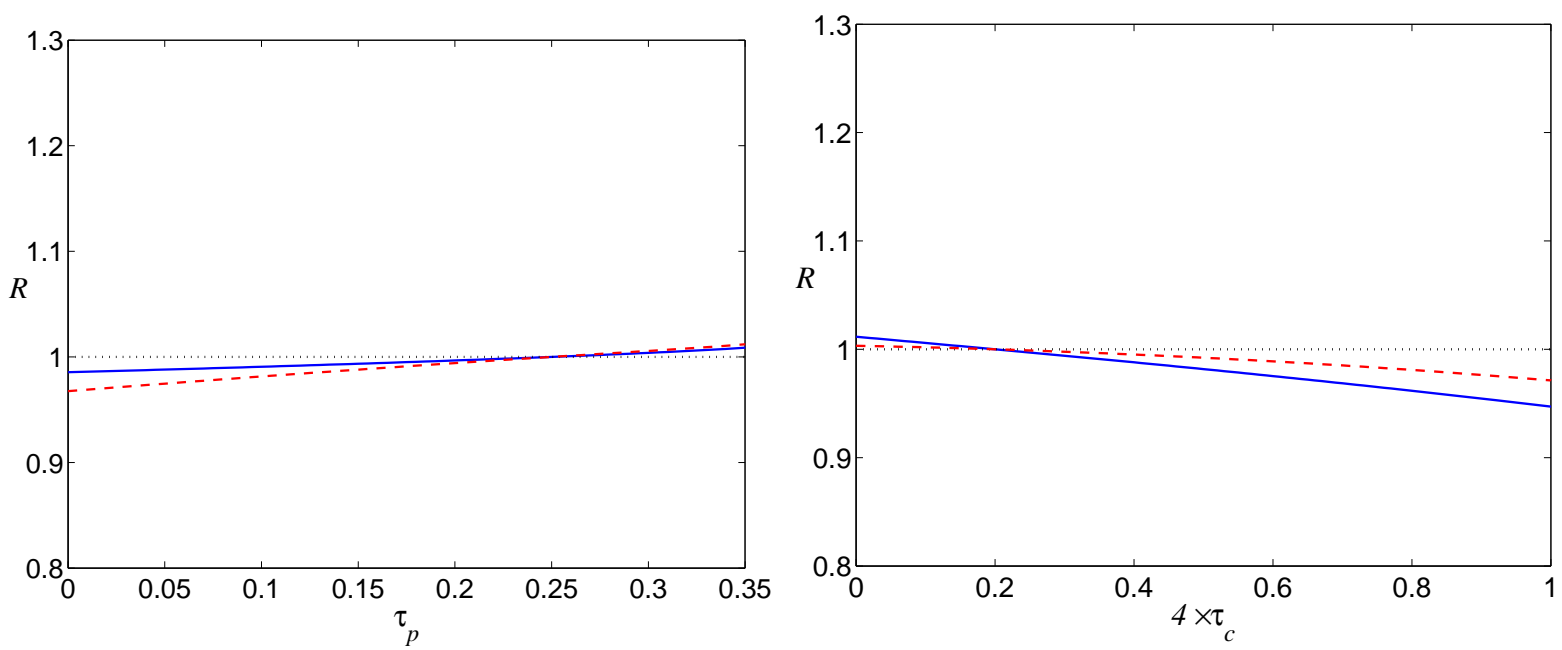

Solid lines: steady-state Laffer curve; dashed lines: NPV Laffer curve. 
Figure 4: LAFFER CURVE FOR $z$

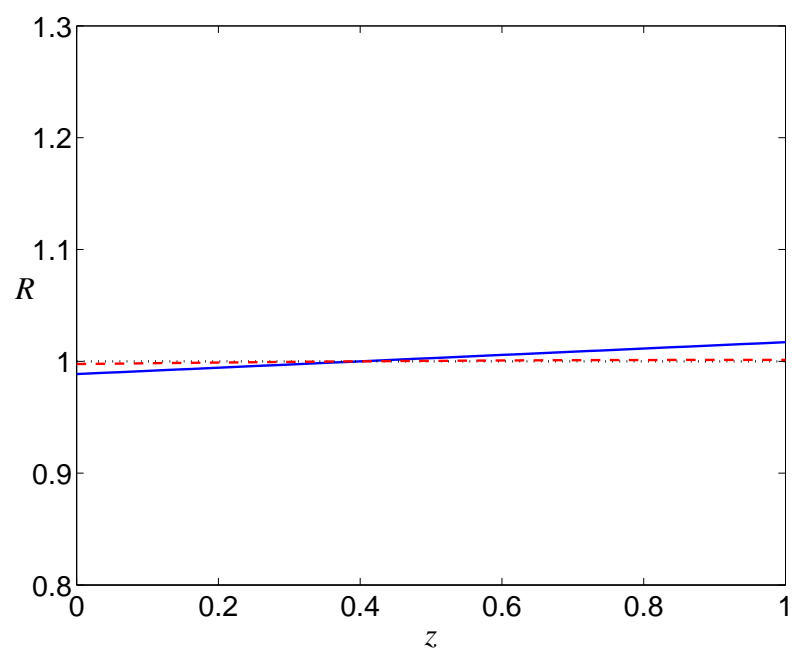

Solid lines: steady-state Laffer curve; dashed lines: NPV Laffer curve.

For capital gains taxation we find, strikingly, that there exists no interior maximum of the Laffer curve for the US. The Laffer curve is continuously falling. While dynamic scoring has already suggested that the US is on the wrong side of the Laffer curve we now find that there is just one side of the Laffer curve. The revenue-maximizing capital gains tax is zero. This is true irrespective of whether adjustment dynamics are taken into account or not. If adjustment dynamics are taken into account the predicted increase of tax revenue from abolishment of the tax decreases from 1.2 percent to 0.3 percent. $^{6}$

Finally, we also observe in Figure 4 a very flat Laffer curve for the investment tax credit (or tax depreciation allowance) $z$. The revenue maximizing tax credit is found at 100 percent when we compare steady-states and at 92 percent when we include adjustment dynamics. These figures, however, conceal the fact that the Laffer curve is basically horizontal. Taking all feedback effects from general equilibrium into account, we conclude that any $z$ leads to about the same total tax revenue. This novel finding suggests that depreciation allowances are a very powerful policy instrument. Changing $z$ entails a large and immediate effect of investment and output and has basically no consequences on the government budget.

In Table 5 we provide a robustness check for our results. Generally, the volatility of the Laffer maximum is quite high. But given that the curves are almost flat this observation is not useful to assess robustness. More suitable is the computed extra gain of tax revenue that

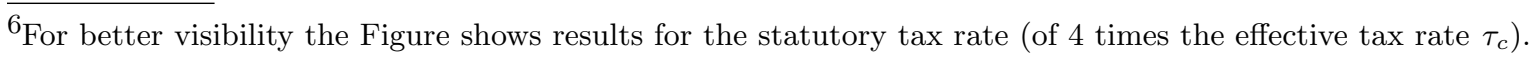


Table 5: Max. of Laffer Curve and Max. Tax Revenue

\begin{tabular}{|c|c|c|c|c|c|c|c|c|}
\hline \multicolumn{9}{|c|}{ Part I: Steady-State } \\
\hline $\operatorname{Tax}$ & $\sigma=1$ & $\phi=1$ & $\sigma=2$ & $\phi=1$ & $\sigma=1$ & $\phi=3$ & $\sigma=2$ & $\phi=3$ \\
\hline & $\operatorname{Tax}$ & max. Rev. & Tax & max. Rev. & Tax & max. Rev. & $\operatorname{Tax}$ & max. Rev. \\
\hline$\tau_{w}$ & 59 & 22 & 57 & 17 & 48 & 9 & 41 & 4 \\
\hline$\tau_{r}$ & 53 & 1.1 & 52 & 0.9 & 49 & 0.6 & 21 & 0.4 \\
\hline$\tau_{c}$ & 0 & 1.1 & 0 & 1.2 & 0 & 1.3 & 0 & 1.4 \\
\hline$z$ & 100 & 1.5 & 100 & 1.7 & 100 & 1.9 & 100 & 2.3 \\
\hline \multicolumn{9}{|c|}{ Part II: Net Present Value } \\
\hline \multirow[t]{2}{*}{ Tax } & $\sigma=1$ & $\phi=1$ & $\sigma=2$ & $\phi=1$ & $\sigma=1$ & $\phi=3$ & $\sigma=2$ & $\phi=3$ \\
\hline & Tax & max. Rev. & Tax & max. Rev. & Tax & max. Rev. & Tax & max. Rev. \\
\hline$\tau_{w}$ & 64 & 28 & 64 & 26 & 52 & 13 & 47 & 8 \\
\hline$\tau_{r}$ & 75 & 6.9 & 80 & 9.2 & 71 & 4.4 & 76 & 5.9 \\
\hline$\tau_{c}$ & 0 & 0.35 & 0 & 0.32 & 0 & 0.57 & 0 & 0.61 \\
\hline$z$ & 94 & 0.17 & 92 & 0.13 & 100 & 0.66 & 100 & 0.76 \\
\hline
\end{tabular}

Tax denotes the tax rate in percent at which revenue is maximized. Max. Rev. is the size of extra revenue collected at the maximum and expressed in percent of status quo revenue.

can be collected at the maximum. Here we observe again that results for capital taxation are relatively robust compared to labor taxation. For example, comparing steady-states, the model predicts a maximum gain of revenue from corporate taxation between 0.4 and 1.1 percent whereas the prediction for the labor tax varies between 4 and 22 percent. The revenue gain from abolishing the capital gains tax is predicted to lie between 1.1 and 1.4 percent when steadystates are compared and between 0.32 and 0.61 percent when transitional dynamics are taken into account. It is thus fair to conclude that the tax can be abolished without harming tax revenue.

\section{Conclusion}

In this paper we have set up a neoclassical growth model suitable to assess revenue effects of capital taxation. While our results at the aggregate level are broadly consistent with the available literature the novel disaggregated view on capital taxation has provided new insights. Generally, some capital taxes are identified to be more distortionary than others. For example, our general equilibrium analysis suggests that corporate taxes can be drastically reduced with little effect on total tax revenue and that the revenue-maximizing tax rate on capital gains is zero. We have tried to explain the general mechanics behind our results with a detailed theoretical analysis of dynamic scoring and we have also demonstrated how robust results are 
against different specifications of preferences and how they change when adjustment dynamics after a tax change are taken into account.

But as always there is plenty of room to extend the basic setup. Some of these extensions have been explored already within the simpler framework of the standard neoclassical growth model (or the $A k$-growth model) without corporate sector and just one tax on capital. For example, it would be interesting to integrate more flexible production functions and externalities (Mankiw and Weinzierl, 2006), alternative financing schemes of tax cuts (Trabandt and Uhlig, 2010, Leeper and Yang, 2008), human capital (Novales and Ruiz, 2002), and productive government expenditure (Bruce and Turnovsky, 1999). We thus believe that scoring capital taxes will remain to be an exciting and challenging field for scholars and policymakers. 


\section{APPENDIX}

The Hamiltonian for maximization of (2) subject to (4)-(5) is:

$$
\begin{aligned}
\mathcal{H}= & \frac{\left(1-\tau_{r}\right)\left(1-\tau_{d}\right)}{\left(1-\tau_{c}\right)} \times \\
& \left\{F(K, A L)-w L-\delta K-r B-a(B / K) B+\left(\dot{B}-\left(1-\tau_{r} z\right) I\right) /\left(1-\tau_{r}\right)\right\}+q_{K} I+q_{B} \dot{B}
\end{aligned}
$$

where $q_{K}$ and $q_{B}$ denote the costate variables associated with capital and debt. Since the Hamiltonian is linear homogenous in $K$ and $B$ the value of equity is $V=q_{K} K+q_{B} B$. In equilibrium, labor supply equals labor demand, i.e. $L=\ell$. Let capital in efficiency units be defined as $k:=K / A$, the debt ratio as $b:=B / K$, and production per efficiency unit as $f(k, \ell):=$ $F(k, \ell), f_{i}(k, \ell)>0, f_{i i}(k, \ell)<0, i=k, \ell$. The first order conditions for optimal choice of investment $(I)$ and employment $(\ell)$ and new debt $(\dot{B})$ are

$$
\begin{aligned}
& w=A\left[f(k, \ell)-f_{k}(k, \ell) k\right] \\
& \frac{\left(1-\tau_{d}\right)\left(1-\tau_{r}^{2} z\right)}{\left(1-\tau_{c}\right)}=q_{K} \\
& -\frac{\left(1-\tau_{d}\right)}{\left(1-t_{c}\right)}=q_{B} \\
& \frac{\left(1-\tau_{r}\right)\left(1-\tau_{d}\right)}{\left(1-\tau_{c}\right)}\left[f_{k}(k, \ell)-\delta+a^{\prime}(b) b^{2}\right]=q_{K} r \frac{\left(1-\tau_{p}\right)}{\left(1-\tau_{c}\right)}-\dot{q}_{K} \\
& -\frac{\left(1-\tau_{r}\right)\left(1-\tau_{d}\right)}{\left(1-\tau_{c}\right)}\left[r+a(b)+a^{\prime}(b) b\right]=q_{B} r \frac{\left(1-\tau_{p}\right)}{\left(1-\tau_{c}\right)}-\dot{q}_{B} .
\end{aligned}
$$

The necessary conditions are sufficient and an interior solution is - if it exists - unique, if the non-maximized Hamiltonian is strictly concave in states and controls. With respect to capital and debt strict concavity of the Hamiltonian requires that total costs of leverage, $a(B / K) B$, are strictly convex in $K$ and $B$, implying:

$$
2 a^{\prime}(b)+a^{\prime \prime}(b) b>0
$$

which is assumed to hold henceforth.

From the first order conditions (??) we derive the optimal debt ratio as an implicit function of the capital labor ratio and the tax legislation.

$$
0=f_{k}(k, \ell)-\delta+a^{\prime}(b) b^{2}-\left[\frac{\left(1-\tau_{r}^{2} z\right)\left(1-\tau_{p}\right)}{\left(1-\tau_{p}\right)-\left(1-\tau_{c}\right)\left(1-\tau_{r}\right)}\right]\left(a(b)+a^{\prime}(b) b\right) .
$$


We investigate the steady state to derive steady state interest rate and dividend ratio. Consumption grows with rate $\gamma$ in steady state. We can derive from equation (10) that

$$
\left(1-\tau_{p}\right) r^{*}=\sigma \gamma+\rho
$$

holds. Inserting this and $\dot{V} / V=\gamma$ in no-arbitrage equation (1) yields

$$
\frac{\left(1-\tau_{d}\right) D}{V}=\frac{\tilde{D}}{V}=\left[\sigma-\left(1-\tau_{c}\right)\right] \gamma+\rho .
$$

Hence, the net dividend ratio at the steady state is constant and changes only with capital gain taxes. 


\section{References}

Agell, J. and M. Persson, 2001, On the analysis of the dynamic Laffer curve, Journal of Monetary Economics 48, 397-414.

Auerbach, A., 2001, Taxation and corporate financial policy, NBER Working Paper 8203.

Baxter, M. and R.G. King, 1993, Fiscal policy in general equilibrium, American Economic Review 83, 315-334.

Bernanke, B. and M. Gertler, 1989, Agency costs, net worth and business fluctuations, American Economic Review, 79, 14-31.

Bruce, N. and S.J. Turnovsky, 1999, Budget balance, welfare, and the growth rate: dynamic scoring of the long-run government budget, Journal of Money, Credit and Banking 31, 162186.

Carlstrom, C.T. and T.S. Fuerst, 1997, Agency costs, net worth and business fluctuations: A computable general equilibrium analysis, American Economic Review, 87, 893-910.

Clausing, K.A., 2007, Corporate tax revenues in OECD countries, International Tax and Public Finance 14, 115-133.

Cooley, Th.F. and G. D. Hansen, 1992, Tax distortions in a neoclassical monetary economy, Journal of Economic Theory 58, 290-316.

Djankov, S., T: Ganser, C. McLeish, R. Ramalho, and A. Shleifer, 2008, The effect of corporate taxes on investment and entrepreneurship, NBER Working Paper 13756.

Gordon, R.H and Y. Lee, 2001, Do taxes affect corporate debt policy ? Evidence form U.S. corporate tax return data, Journal of Public Economics 82, 195-224.

Gordon, R.H and Y. Lee, 2007, Interest rates, taxes and corporate financial policies, National Tax Journal, 65-84.

Graham, J.R., 2000, How big are the tax benefits of debt?, Journal of Finance 55(5), 1901-1941.

Graham, J. R., 2006, Taxes and corporate finance, in: B. E. Eckbo (ed.): Handbook of Corporate Finance - Empirical Corporate Finance, Amsterdam: Elsevier Science.

Greenwood, J. and G.W. Huffman, 1991, Tax analysis in a real business cycle model, Journal of Monetary Economics 27, 167-190.

House, C.L. and M.D. Shapiro, 2008. Temporary investment tax incentives: theory with evidence from bonus depreciation, American Economic Review 98, 737-768.

IRS, 2008, Internal Revenue Bulletin: 2008-45 (http://www.irs.gov/irb/2008-45_IRB/ar14.html).

Leeper, E.M. and S.-C. Yang, 2008, Dynamic scoring: alternative financing schemes, Journal of Public Economics 92, 159-182.

Mankiw, N.G., and M. Weinzierl, 2006, Dynamic scoring: a back-of-the-envelope guide, Journal of Public Economics 90, 1415-1433. 
McGrattan, E.R., 1994, The macroeconomic effects of distortionary taxation, Journal of Monetary Economics 33, 573-604.

McGrattan, E.R., and E.C. Prescott, 2005, Taxes, regulations, and the value of U.S. and U.K. corporations, Review of Economic Studies 72, 767-796.

Mendoza, E.G., and L.L. Tesar, 1998, The international ramifications of tax reforms: supplyside economics in a global economy, American Economic Review 88, 226-245.

Mountford, A. and H. Uhlig, 2008, What are the effects of fiscal policy shocks? NBER Working Paper 14551.

Novales, A. and J. Ruiz, 2002, Dynamic Laffer curves, Journal of Economic Dynamics and Control 27, 181-206.

OECD, 1991, Taxing Profits in a Global Economy: Domestic and International Issues, OECD, Paris.

Poterba, J.M., 2004, Taxation and corporate payout policy, American Economic Review, Papers and Proceedings 94, 171-175.

Romer, C.D. and D.H. Romer, 2010, The macroeconomic effects of tax changes: estimates based on a new measure of fiscal shocks, American Economic Review 100, 763-801

Sinn, H.W., 1987, Capital income taxation and resource allocation, North-Holland, Amsterdam.

Strulik, H., 2003, Capital tax reform, corporate finance, and economic growth and welfare, Journal of Economic Dynamics and Control 28, 595-615.

Strulik, H., 2008, The credit channel of capital tax policy, Journal of Public Economic Theory forthcoming.

Strulik, H. and T. Trimborn, 2010, Anticipated tax reforms and temporary tax cuts: a general equilibrium analysis, Journal of Economic Dynamics and Control forthcoming.

Trabandt, M. and H. Uhlig, 2010, How far are we from the slippery slope? The Laffer curve revisited, Discussion paper, European Central Bank.

Trimborn, T., K.-J. Koch, and T.M. Steger, 2008, Multi-dimensional transitional dynamics: A simple numerical procedure, Macroeconomic Dynamics, 12, 1-19.

Turnovsky, S.J., 1982, The incidence of taxes: A dynamic macroeconomic analysis, Journal of Public Economics 18, 161-194.

Turnovsky, S.J., 1990, The effects of taxes and dividend policy on capital accumulation and macroeconomic behavior, Journal of Economic Dynamics and Control 14, 491-521. 